\title{
Characterization, Phytopathogenicity and Host Range Studies of Neoscytalidium Dimidiatuml. (Botryosphaeraceae) Associated With Dieback of Lebbeck Trees (Albizia Lebbeck L. Benth) in Saudi Arabia
}

Khalid E. Hamed ( $\sim$ kh.mohammed@qu.edu.sa )

Qassim University https://orcid.org/0000-0002-5278-0104

Abdullah Alsoim

Qassim University College of Agriculture and Veterinary Medicine

Ahmed Rogaibah

Qassim University College of Agriculture and Veterinary Medicine

\section{Research Article}

Keywords: Botryosphaeriales, coelomycetes, lebbeck tree, Neoscytalidium dimidiatum, pathogenicity

Posted Date: July 21st, 2021

DOI: https://doi.org/10.21203/rs.3.rs-631626/v1

License: (1) (i) This work is licensed under a Creative Commons Attribution 4.0 International License. Read Full License 


\section{Abstract}

A survey in 2016 showed that more than $80 \%$ lebbeck trees inside the main campus of Qassim University were wilted and dead. Symptoms of dieback, root rot, stem cankers and decline were observed in the trees. The trunks exhibited black masses of spores which soon spread to other, healthy trees. A fungus, having arthroconidial and asexual synanamorph characteristics, and was identified as Neoscytalidiumdimidiatum KSA of the class Coelomycetes within the family Botryosphaeraceae and was subsequently isolated from the infected lebbeck trees. Six-year-old lebbeck seedlings were inoculated with the N. dimidiatum KSA isolate. Symptoms of chloroses followed by dropping leaves appeared four weeks after inoculation. The fungus re-isolated from the infected seedlings expressed the same morphological characteristics on the culture media as the N. dimidiatum KSA isolate. A host range study involving six different tree species were inoculated under growth chamber conditions using the identified isolate of the N. dimidiatum KSA fungus. Four weeks after the inoculation, three of these species exhibited wilting and died. To the best of our knowledge, this study is the first to report on N. dimidiatum in Saudi Arabia.

\section{Introduction}

The genus Albiziaincludes about one hundred and fifty species, mostly trees and shrubs native tothe tropical and subtropical regionsof Asia and Africa\{23\}.Albizia lebbeck is partiallyidentifiedwith deciduous and semi-deciduous forestswithin Asia from eastern Pakistan through India to Sri Lanka and Myanmar. The tree has been introduced as an ornamental and plantation tree throughout tropicaland northern subtropical regions which includeCentral America, Colombia, Venezuela and Brazil. \{13\}.

Albizia lebbeckis a fast-growing, medium-sized deciduous tree with nitrogen fixation and assimilation capabilities. The treehasan umbrella-shaped crown of thin foliage and a smooth, finely fissured trunk withgreyish-brown bark. Depending on site conditions, annual crown cover increases can spread from 0.5 to $2.0 \mathrm{~m}$.Individual trees attain an average maximum height of $18-25 \mathrm{~m}$ and $50-80 \mathrm{~cm}$ d.b.h.The species grows well at altitudes up to $1500 \mathrm{~m}$ a.s.l. in sites receiving $500-2500 \mathrm{~mm}$ annual rainfall and it can tolerate both light forest and drought conditions. Although it grows poorly in heavy clay soils, it tolerates saline, sodic or lateritic soils. The tree developswell in moist,well-drained soil. Its leaves, seeds, bark and roots are all used in traditional Indian medicine $\{23\}$ for treating various kinds of ailments. The bark is used for toothache, piles, diarrhoea and diseases of the gum. Decoctions of the leaves and bark are used to treat bronchial asthma and other allergic disorders $\{2\}$. In their folk medicine, the Segen people of Ethiopia use the bark of the tree in the management of salmonellosis. Various studies have indicated thatdifferent parts of the barkcovering different regions of the stem exhibitdifferent activities $\{25\}$.

Many years ago, A. lebbeck was introduced to central Saudi Arabiafrom India and it has adapted well to the severe environmental conditions $\{14\}$. The tree is characterized by its resistance to heat and drought andtolerance of harsh environments. 
The Botryosphaeriaceaeinclude various morphologically diverse fungi that act as pathogens, endophytes or saprobes, mainly on woody hosts. They are found in all geographical and climatic areas of the world, with the exception of the polar regions. Their persistent association with plant diseases has stimulated substantial interest in these fungi, much of which has been focused on the systematics of species and genera $\{27\}$.

Neoscytalidium hyalinum is a plant fungus belonging to the family Botryosphaeriaceae. Nattrass $\{24\}$ first specifiedit by the name Hendersonula toruloidea.In 1970, Gentles and Evans $\{16\}$ reported dermatomycosis in patients from tropical regions, followed byCampbell and Mulder $\{3\}$, who presented a new species,Scytalidium hyalinum, which was similartothat causing theclinical lesions.Intense discussions on nomenclature have been conducted starting with theseearly descriptions of arthroconidia and pycnidial synanamorphs. Sutton and Dyco $\{38\}$ changed H. toruloidea to Nattrassiamangiferae for those mycelial synanamorphs named Scytalidiumdimidiatum. Farr et al. $\{15\}$,using phylogenetic analysis,concurred on Nattrassia mangiferae. Furthermore,they presented the name.

Fusicoccumdimidiatum to replace $S$. dimidiatum. In a revision of the taxonomy of Botryeospheraceae, Crous et al.\{5\} proposed the genus Neoscytalidiumto replaceS. dimidiatumwithN. dimidiatum.

A genus wasproposed by Crous et al. $\{5\}$ for a fungusrecently reported in Brazil that forms Scytalidiumlike synanamorphs in the aerial mycelia and Fusicoccum-like conidia in the pycnidia\{20\}.A short time ago, the species $N$. hyalinumwas reassigned as $N$. dimidiatum because $S$. hyalinum was phylogenetically indistinguishable from $N$. dimidiatum. Therefore, the older designationwas considered \{27\}. Hyalinum might be conspecific and a new name ( $N$. dimidiatumvar. hyalinum) has been suggested $\{21\}$.

Diseases associated with this fungus are reported to be more common in tropical countries. It has been associated with freeze-damaged branches of citrus spp. in California, and appears to be a wound pathogen of this host. In Italy,it causes shoot blight, canker and gummosis disease of citrus $\{28\}\{29\}$.

Neoscytalidium hyalinumaffects abroad range of plant species, causing branch wilting, cancer, dieback and death of treesPunithalingam and Waterson $\{31\}$; Reckhaus $\{33\}$; Elshafie and Ba-Omar $\{12\}$.Initially, the fungus was reported under the nameNattrassia mangifera on mango trees in India, then in citrus trees in California\{38\} and later, the fungus was found to cause cancer on Pacific madrone (Arbutus menziesii) in the USA \{11\}. Dieback symptoms on mango trees (Mangifera indica) and Ficus carica in Australia were attributed to N.dimidiatum $\{32\}$.

The same pathogen was recently reported on lebbeck trees(A. lebbeck),Delonix regia, Ficus carica, Ficus spp., Peltophorum petrocarpum and Thespesia populena in the Sultanate of Oman $\{12\}$. The same symptoms were observed onlebbeck trees inside the main campus of Qassim University in Buraydah, Central Saudi Arabia.

The aim of this study was to identify and characterize the Botryosphaeriaceae occurring on A.lebbeck inSaudi Arabia using themorphology of the anamorph stages,PCR-RFLP analysis, DNA sequence comparisons, host range studies and the pathogenicity of these fungi. 


\section{Materialand Methods}

\section{Symptomatology, sample collection and isolation}

The branches and main stems of $A$. lebbeckexhibitedextensive dieback, decline and cracking as the main symptoms of the samplescollected throughout the surveyconducted on the main campus of Qassim University in Buraydah in central Saudi Arabia. The dieback symptomson the lebbeck trees were predominant over $80 \%$ of thesurveyed area. Small specimens $(4-5 \mathrm{~mm})$ from the bark of the main stems and live tissue from the brancheswere collectedin polythene bags and transported to the phytopathology laboratory of theQassim University College of Agriculture and VeterinaryMedicine for initial fungal isolation and further analysis. In addition, pure cultures of the fungus were sent to the Leibniz Institute DSMZ - German CollectionofMicroorganisms and Cell Cultures, Braunschweig, Germany, for molecular analysis and deposition. Thesurfacesof thespecimenswere disinfected for $1 \mathrm{~min}$ in $70 \%$ ethanol followed by 3 min in 1\% sodium hypochloride andthereafter washed thoroughly two times withrenewedsterile distilled water and dried on sterile tissues.Using sterile forceps, the pieces were placed onto sterilized disposable petri dishescontainingautoclaved potato dextrose agar (PDA, Oxoid, UK) to which was added $0.5 \mathrm{~g} / \mathrm{L}$ streptomycin sulphideand thenincubatedat $\pm 25^{\circ} \mathrm{Cfor} 72 \mathrm{~h}$.

\section{Morphological analysis}

The isolate was then placed in petri dishes containing autoclaved $2 \%$ water agar (WA Agar, Oxoid, England)using a sterile casuarina needle and incubated for three weeks at $\pm 25^{\circ} \mathrm{Cto}$ encourage sporulation of the culturesfor conidial characteristics. In order to identify the species, the variance of morphological characteristics were detected using a light microscope (OLYMPUS CX31)equipped witha digital camera (OLYMPUS EVOLT330) and images were taken. The isolate was deposited in the Leibniz Institute DSMZ - German CollectionofMicroorganisms and Cell Cultures, Braunschweig, Germany, under the accession number DSM 104095.

\section{Pathogenicity tests}

An identified isolate of N.dimidiatumKSA based on PCR, anamorph morphology and DNA sequence comparisons was used for thepathogenicity trial to fulfil Koch's postulates. The 7-day-old incubated isolate grown on aPDA medium at $25^{\circ} \mathrm{C}$ was used for inoculations. Six-month-old lebbeck tree seedlings were chosen for pathogenicity tests under growth chamber conditionsof $28^{\circ} \mathrm{C}$ and $15 \mathrm{~h}$ daylight. The height of the trees was approximately $90 \mathrm{~cm}$ and the diameters of the main stems approximately $10 \mathrm{~mm}$. The seedling trees were allowed toacclimatizeunder thegrowth chamber conditionsfor one month before the inoculations were performed.A sterile cork borer was used to pick up6-mm-diameterdiscs of the PDA medium with the fungal growth of $N$.dimidiatumKSA isolates including mycelia. The inoculation was performed on thestems of 10 trees by removing the bark $5 \mathrm{~cm}$ above soil levelto disclose the cambium. Five trees were also inoculated with a sterile PDA medium and kept as controls. The areas of inoculation were wrapped tightly with plastic parafilm(Pechiney Plastic Packaging) to prevent drying and contamination. Six weeks post inoculation, the bark of the inoculated trees was removed from $5 \mathrm{~cm}$ 
above and below the wounded area and small samples from all inoculated and non-inoculated trees wereplated on a PDA medium for fungal isolation.

\section{Host range studies}

The tree species used for the host range studies were selectedbased on ecological importance to the environment of Saudi Arabia andtheir potential susceptibility to the pathogen. Ten healthy seedling treesof Ficus infectoria, Moringa oleifera, Casuarina cunninghan, Enterlobium cyclocorpum, Eucalyptus tereticornis and Ficus nitida agedabout six monthswere collected from the forests nurseryofthe College of Agriculture and Veterinary Medicine farm. The seedling trees were grown in plastic potsfilled with a 2:1 mixture of sand and clay soil. The seedling trees were maintainedunder growth chamber conditions at $26^{\circ} \mathrm{C}$ and $30-60 \%$ relative humidity and irrigated once a week. Eight out of the ten trees of each species were inoculated using the identified isolate of N.dimidiatumKSA as described previously and the remaining two seedlings of each species were left uninoculated for comparison. Monitoring for the development of symptoms was done weekly. Fungal re-isolation was carried out to verify Koch's postulates.

\section{DNA extraction and PCR sequencing for identification of isolates}

Pure cultures were maintained on $2 \%$ malt extract agar and harvested directly from the plates. Genomic DNA was extracted using the MasterPure ${ }^{\mathrm{TM}}$ Yeast (Epicentre, for Fungi and Yeasts) DNA Isolation Kit. The strain was PCR amplified and sequenced, targeting the partial gene of the translation elongation factor alpha 1 using primers EF1-728Fand EF1-986R \{4\}.

The PCR mixtures contained Taq and PCR buffer (Takara Bio Inc., Kusatsu, Japan), 5pM of each primer (Eurofins),200 $\mu \mathrm{M}$ dNTPs (Roche), 40-200 ng of genomic DNA and nuclease-free water. The PCR was performed with an initial denaturation step for $2 \mathrm{~min}$ at $94^{\circ} \mathrm{C}$, followed by $25-35$ cycles of denaturation for $1 \mathrm{~min}$ at $94^{\circ} \mathrm{C}, 45$-s primer annealing, and elongation for $1 \mathrm{~min}$ at $72^{\circ} \mathrm{C}$. The quality of the PCR amplicons was checked in 1.2\% agarose gel stained with GelStar (Lonza, Switzerland) under UV light using a $1 \mathrm{~kb}$ ladder (Gene Ruler 1, Thermo Scientific, Germany). The amplicons were purified using the QuiaQuick purification kit (Quiagen, Germany). Sequences were generated with an AB 3730 DNA analyzer (Applied Biosystems, Foster City, CA) and the AmpliTaq FS Big Dye terminator cycle sequencing kit. To type strain references when appropriate,all sequences were used as queries in the GenBank and MycoBank sequence similarity search tool BLAST [http://blast.ncbi.nlm.nih.gov/Blast.cgi] with default stringency and restrictions.

\section{Phylogenetic analysis}

Phylogenetic relationships were assessed using the ARB software package (Ludwig et al. 2004). All sequences were aligned using Fast Aligner/ClustalW and Muscle (Edgar 2004) implemented in ARB V1.06. All alignments were thoroughly examined and manually optimized according to primary and 
secondary structure information calculated by ARB. Ambiguously aligned nucleotide characters were excluded manually prior to phylogenetic analyses. The jModeltest 2.1.1 (Darriba et al. 2012) was used for the selection of the model of nucleotide substitution that best fit the sequence data, employing the Akaike Information Criterion (Posada and Buckley 2004). Maximum Likelihood analyses were performed with ARB using RAxML(Randomized Accelerated Maximum Likelihood) 7.0.3 (Stamatakis 2006) applying the GTRGAMMAmodel of sequence evolution for the combined data set. Searches were performed with random sequence additions and 100 replicates. Branch support was tested with 1000 replications on bootstrapped data sets.

\section{Results}

\section{Symptomatology and fungal isolation}

A survey of the lebbeck trees planted as avenue shade on the main campus of Qassim University in Buraydah in central Saudi Arabia revealed that more than $80 \%$ of the trees were wilted and dead. Symptoms of dieback, root rot, stem canker and decline were apparent (Fig. 1a). These symptoms included yellowing branches and browning of leaves and subsequent leaf fall (Fig. 1b). Consequently, rapid death of the branches and cracking of the main trunkswere observed (Fig. 1c).A black mass of fungal spores could be observed on the trunk (Fig. 1f)which soon spread by wind or water to other,healthy trees. The bark of the main roots presentedthe same symptoms. The fungus N.dimidiatumwas isolated from the cracking stems of the ten representative symptomatic lebbeck trees exhibiting dieback. The isolate and its relation to other species of Botryosphaeriaceaewere later confirmed by DNA sequencing.

\section{Culture characteristics and morphology}

The colonies on the PDA media were initially whitish, butgradually turned blackish afterthree days (Fig. 2a). They were flatand attained radial growth with threadlike forms onthe margin in 3-5 days at $25^{\circ} \mathrm{C}$.For inducing the sporulation, an identified single spore culture was placed on the surface of $2 \%$ water agar medium using a sterile casuarina needle and incubated at $25^{\circ} \mathrm{C}$.A chain of cylindrical or spherical arthroconidia appeared on the branched aerial mycelium.Seen under microscopy, the hyaline conidia freed from pycnidia weretruncate at the base,immersed,dark to darkbrown with smooth thick walls, at first aseptate andlater becoming septatewith central dark brown septa(Fig. 2b). Characteristic of the synasexual morph of coelomycetes, the stromatic conidiomata seen were immersed,lately decrepitate, dark brown or black, spherical, 2-3 mm in diameter with thick, black cell layers and irregular outer walls, while the inner walls were thin and hyaline(Figs. 2c, d).

\section{Pathogenicity tests}

Theinoculated lebbeck tree seedlings were assessed after tendays post inoculation. The N.dimidiatumelicited symptoms similar to those shown on the trees naturally infected. Ten days after inoculation, symptoms were starting to appear on four out of eight stems of the inoculated seedlings.Firstly, leaves and branches developed chlorosis, startingwith old leaves, and subsequent leaf 
fall, and four weeks later, all eight inoculated lebbeck tree seedlings werewilted and bareof leaves,while the uninoculated control seedlings showed no symptoms under test conditions. Re-isolation of the fungus from the stems of the infected lebbeck seedlingsperformed on PDA media to accomplish Koch's postulates revealed the fungus to be N.dimidiatum(Fig. 2).

\section{Host range}

The different host plant species examined exhibited symptoms as follows.In Ficus infectoria, all seedling treesinoculated with $N$. hyalinum showedchlorosis in the leaves followed by necrosis two weeks after inoculation. Canker of the main stem extending to the crown was observed. Thereafter,all the seedlings were completely wilted. At the inoculation site under the bark,a sooty coat of black spores was found coming off in layers (Fig. 3a). In Moringa oleifera, symptoms were seen ten days after inoculation.Chlorosis of the leaves and then leaf fall developed in $50 \%$ of the inoculated seedlings. A month later, $80 \%$ of the seedlings were completely wilted, while the controls remainedfree of any symptoms (Fig. 3b).In Enterlobium cyclocorpum, leaves of the inoculated seedlings initially became pale and developed chlorosis and necrosis followed byleaf dropthree weeks after inoculation.In five to six weeks, $75 \%$ of the seedlings inoculated under the bark of the stem were completely wilted, whereas the control seedlings did not show any symptoms (Fig. 3c). TheCasuarina equstifolia, Eucalyptus tereticornis and Ficus nitidaseedlings did not produce any symptoms under test conditions and were indistinguishable from the uninoculated seedlings (Fig. 3d).

Re-isolation from the infected seedlings on PDA media confirmed that $N$. hyalinum was the prevalent fungal pathogen isolated; however, the uninoculated seedlings

\section{DNA sequencing and phylogenetic analysis}

Sequencing of the elongation factor alpha 1 gene region and phylogenetic analysis confirmed that our isolate wasN. dimidiatum (Penz.) Crous \& Slippers, a member of the family Botryosphaeriaceae (Fig. 4).Some of the closest BLAST hits for our isolate were identified as N. hyalinum. According to Huang et al. $\{18\}, N$. hyalinum is synonymous with $N$. dimidiatum due to the con-specificity of the two.

\section{Discussion}

When first observed, it was striking that most of the lebbeck trees of different ages planted on the main campus of Qassim University at Al-Mulayda (Buraydah), Qassim, central Saudi Arabia, were wilted or dead. Initially, the trees exhibited symptoms ofyellowing and chlorosis on branches and leaves, which turned brown and subsequently suffered leaf fall followed by dieback, stem canker and decline (Fig. 1a). Consequently, quick death of the branches and cracking of the main trunkswere observed. The trunksexhibited a black mass of fungal spores through the cracking bark (Fig. 1c). The symptoms described here are identical to those reported on lebbeck trees in the Sultanate of Oman by Elshafie and Ba-Omar $\{12\}$ and likewise byAbbasher et al. \{1\}in ficus trees, Giha $\{17\}$ in mango trees (Mangifera indica), and El Trefee\{10\}in the fruit orchards of Sudan. 
In the present study, for the first time, a new isolate of N.dimidiatumKSA wasisolated from infected trees andreported as causing dieback and mortality of lebbeck trees in Saudi Arabia based on symptomatology, phytopathogenicity, host range studies, DNA sequencing, phylogenetic analysis and morphological characteristics of the coelomycetous asexual morph with stromatic dark brown to black, black and erumpent conidiomata, and ellipsoidal to oval and hyaline conidia. The fungus Natrrassiamangifra has a wide geographical range in Africa, Asia, and North and South America $\{31\}$. The fungus was first recorded by Nattrass\{24\}as causing rapid death on deciduous trees in Egypt, by Sutton and Dyko $\{38\}$ as causing the same on mango trees in India and theUnited States.

Neoscytalidium dimidiatum, belonging to the Botryosphaeriaceaefamily, has been reported to have a wide host range, including apple, banana, citrus, fig, and mango $\{37\} ;\{29\} ;\{32\} ;\{27\}$. The isolate $N$. hyalinum reported herewas characterized by $1-2$ septa, brown conidia in the coelomycete morph and holothallic fragmentation of undifferentiated hyphae on potato dextrose agar. In this study,N.dimidiatumhad thedimensions of conidia, arthroconidial sporesand conidiogenous cells typicalof descriptions of this species in previous studies $\{26\} ;\{27\}$.

Based on phylogenetic analysis of the elongation factor alpha 1 gene region of the DSM104095 isolatewith 70 othersequencesof the members of Botryosphaeriaceae available in the NCBI/GenBank, it wasdemonstrated that $N$. dimidiatumtogether with the other fiveisolates in the genus, specifically $N$. dimidiatum,constitute a separate clade in the tree reconstruction (Fig. 4). All sequences of isolates within this cluster are more closely related to each other than to other members of Botryosphaeriaceaeor other species of the genus Neoscytalidium. Some of the closest BLAST hits for our isolate were identified asN. hyalinum.Regarding $N$. hyalinum, Crous et al.\{5\}commented that Scytalidiumhad a polyphyletic feature and introduced Neoscytalidium to transform Scytalidium dimidiatumto N. dimidiatum.According to Huang et al. $\{18\}, N$. hyalinum is synonymous with $N$. dimidiatum due to the con-specificity of the two isolates.Madrida et al.\{21\} suggested that $S$. dimidiatum and $S$. hyalinum could be synonymous, which also agreed with Phillips et al. $\{27\}$, who considered them as members of the same species and joined them under the nameN. hyalinum.

Neoscytalidium dimidiatumis considered an important threat to the sustainability of $A$. lebbecktrees and other flora in Saudi Arabia. Slippers and Wingfield $\{35\}$ and Slippers et al.\{34\}reported that this funguswas capable of infecting native and introduced or cultivated hosts and seemed to move easily between different regions and provinces. The results of this study can provide a base for further work on managing the diseases caused by the Botryosphaeriaceae in Saudi Arabia.

El Gamal et al. $\{9\}$ reported that thelebbeck trees (A. lebbeck) imported from India to Saudi Arabia as an ornamental tree were well acclimatized to the hot environmental conditions of the central region of Saudi Arabia. It was clear that water stress, high temperatures and wind had influenced the incidence and severity of the disease $\{22\}$. The extreme climate of the central region of Saudi Arabia in addition to stress factors may have contributed to the susceptibility of the lebbeck trees to the dieback disease associated 
with $N$. dimidiatum. This is the first report of $N$. dimidiatumassociated with lebbeck dieback in Saudi Arabia.

Over the next 50-100 years, climatic change is expected to exert a passive influenceon the extent of forest land in Saudi Arabia. An increase in the frequency of natural phenomena such as drought, sand storms, fire and flood will lead to increased dieback in forests and woodlands, spread of diseases, changesin type and number of species, a drop in productivity and a reduction in biodiversity $\{6\}$.

\section{Declarations}

\section{Acknowledgements}

The authors would like to thank Dr. Baschien Christianefrom the Leibniz Institute DSMZ - German CollectionofMicroorganisms and Cell Cultures, Braunschweig, Germany, for performing and editing the PCR, sequencing, and phylogenetic analysis of the isolate DSM104095 present in this study.

\section{Author contributions}

$\mathrm{KEH}, \mathrm{ASA}$ and AAR Conceptualiza-tion; KEH conceived the idea. KEH, ASA and AAR collected all the materials. KEH, ASA and AAR wrote the paper, and $\mathrm{KEH}, \mathrm{ASA}$ and $\mathrm{AAR}$ revised the manuscript.

\section{Funding}

Not applicable.Compliance with ethical standards

\section{Conflict of interest}

All authors declare that they have no conflict of interest.

\section{References}

1. Abbasher AA, Husian MM, ZarougMS,Zahran EB.2013. Prevalence and etiology of branch wilt disease (Nattrassia mangiferae) on tree species in wad Medani Area, Sudan. JAVS 14 (1)

2. Bobby MN, Wesely EG, Johnson M (2012) In vitro antibacterial activity of leaves extracts of Albizia lebbeck Benth against some selected pathogens. Asian Pac J Trop Biomed 2(2):S859-S862

3. Campbell CK, Mulder JL (1977) Skin and nail infection by Scytalidiumhyalinum sp. novSabouraudia 15:161-166

4. Carbone I, Kohn LM (1999) A method for designing primer sets for speciation studies in filamentous ascomycetes. Mycologia 91(3):553-556

5. Crous PW, Slippers B, Wingfield MJ, Rheeder J, Marasas WFO, Philips AJL, Alves A, Burgess T, Barber P, Groenewald JZ. 2006.Phylogenetic lineages in the Botryosphaeriaceae. Stud Mycol. 55: 235-253 
6. Darfaoui El M, Al Assiri A (2010) Response to climate change in the Kingdom of Saudi Arabia. A report prepared for FAO-RNE: 1-17

7. Darriba D, Taboada GL, Doallo R, Posada D (2012) jModelTest 2: Moremodels, new heuristics and parallel computing. Nat Methods 9(8):772

8. Edgar RC (2004) MUSCLE: Multiple sequence alignment with high accuracy and high throughput. Nucleic Acids Res 32(5):1792-1797

9. El Gamal AM, Abd El Halim A, Kalil O, Basudan A, Al Rehaily M, Ahmad K, El Tahir S, Al-Massarani W, Abdel-MageedA. 2015.Novelß-lactam derivative, albactam from the flowers of Albizia lebbeck with platelets anti-aggregatory activity in vitro. Pak J Pharm Sci. 28:745-753

10. El Trefee MA (2009) Studies on mango branch wilt disease caused by Nefusicoccum mangiferae [master's thesis].SudanAcademy of Sciences

11. Elliott M, Edmonds RL, Mayer S (2002) Role of fungal diseases in decline of Pacific madrone. NorthwestSci.76:293-303

12. Elshafie AE, Ba-Omar T (2001) First report of Albizia lebbeck dieback caused by Scytalidium dimidiatum in Oman. Mycopathologia 154(1):37-40

13. Faisal M, Singh PP, Irchahaiya R (2012) Review on Albezia lebbeck a potent herbal drug. IRJP 3(5):63-68

14. Farag M, El Gamal A, Kalil A, Al-Rehaily A, El Mirghany O, El Tahir K (2013) Evaluation of Some Biological Activities of Albizia lebbeck Flowers. PP.4: 473-477

15. Farr DF, Elliot M, Rossman AY, Edmonds RL (2005) Fusicoccumarbuti sp. nov. Causing cankers on Pacific madrone in western North America with notes on Fusicoccum dimidiatum, the correct name for Scytalidium dimidiatum and Nattrassia mangiferae. Mycologia 97:730-741

16. Gentles JC, Evans EGV. 1970.Infection of the feet and nails with hendersonula toruloidea. Sabouraudia 8(1): 72-75

17. Giha $\mathrm{OH}$ (1975) Hendersonula toruloidea associated with a serious wiltdisease of shade trees in Sudan. Plant Dis Rep 59:52-52

18. Huang S-K, Tangthirasunun N, Phillips AJL, Wanasinghe DaiD-Q, Wen DN, Kang T-C J-C (2016) Morphology and Phylogeny ofNeoscytalidiumorchidacearum sp. nov. (Botryosphaeriaceae). Mycobiology44(2): 79-84. http://doi.org/10.5941/MYC0.2016.44.2.79

19. Ludwig W, Strunk O, Westram R, Richter L, Meier H, Yadhukumar, Buchner A, Lai T, Steppi S, Jobb G et al (2004) ARB: A software environment for sequence data. Nucleic Acids Res 32(4):1363-1371

20. Machado AR, Pinho DB, Dutra DC, Pereira OL (2012) Collar and root rot caused by Neoscytalidium dimidiatum in the biofuel plant Jatrophacurcas. Plant Dis 96:1697

21. Madrida H, Ruíz-Cendoyaa M, Canoa J, Stchigel A, Orofinob R, Guarroa J. 2009.Genotyping and in vitro antifungal susceptibility of Neoscytalidiumdimidiatum isolates from different origins. Int JAntimicrob Ag. 34(4): 351-354

22. Migahid AM (1996) Flora of Saudi Arabia, 4th edn. King Saud University Press, Riyadh (KSA) 
23. Migahid AM (1989) Flora of Saudi Arabia: ALBIZIA; Al- bizia L, 3rd edn. Riyadh University Publication, Riyadh (KSA), p 8

24. Nattrass RM (1933) A new species of Hendersonula (H. toruloidea) on deciduous trees in Egypt. Trans Br Myco Soc 18:189-198

25. Padamanabhan V, Ganapathy M, Evanjelene VK. 2013.Preliminaryphytochemical and anti- bacterial studies on flowers and pods of Albizia lebbeck (Benth). IJETAE 3(9):541-544

26. Pavlic D, Wingfield MJ, Barber P, Slippers B, Hardy GESJ, Burgess TI (2008) Sevennew species of the Botryosphaeriaceae from baobab and other native trees inWestern Australia. Mycologia 100:851866

27. Phillips AJL, Alves A, Abdollahzadeh J, Slippers B, Wingfield MJ, Groenewald JZ, Crous PW. 2013.The Botryosphaeriaceae: Genera andspeciesknown from culture. Stud Mycol. 76: 51-167

28. Polizzi G, Aiello D, Castello I, Vitale A, Groenewald JZ, Crous PW (2011) Occurrence,molecular characterisation, and pathogenicity of Neoscytalidium dimidiatum onCitrus in Italy. ISHS ActaHortic 892:237-243

29. Polizzi G, Aiello D, Vitale A, Giuffrida F, Groenewald JZ, Crous PW (2009) First reportof shoot blight, canker, and gummosis caused by Neoscytalidium dimidiatum oncitrus in Italy. Plant Dis 93:1215

30. Posada D, Buckley TR (2004) Model selection and model averaging in phylogenetics: Advantages of Akaike information criterion and Bayesian approaches over likelihood ratio tests. SystBiol 53(5):793-808

31. Punithalingam E, Waterston JM (1970) CMI descriptions of pathogenic fungi and bacteria No. 274. In: Hendersonula toruloidea. Commonwealth Mycological Institute, Kew (UK)

32. Ray JD, Burgess T, Lanoiselet V (2010) First record of Neoscytalidiumdimidiatum and N. novaehollandiae on Mangiferaindica and N. dimidiatum onFicus carica in Australia. Australas Plant Dis Notes 5:48-50

33. Reckhaus P (1987) Hendersonula Dieback of Mango in Niger. Plant Dis 71:1045

34. Slippers B, Burgess TI, Pavlic-Zupanc D, Alhumada R (2009) A diverse assemblage of Botryosphaeriaceae infect Eucalyptus in native and non-native environments. South Forests 71(2):101-110

35. Slippers B, Wingfield MJ (2007) Botryosphaeriaceae as endophytes and latentpathogens of woody plants: Diversity, ecology and impact. Fungal BiolRev 21(90):106

36. Stamatakis A (2006) RAxML-VI-HPC: Maximum likelihood-based phylogenetic analyses with thousands of taxa and mixed models. Bioinformatics22(21): 2688-2690

37. Sutton BC (1980) The Coelomycetes: Fungi imperfecti with acervuli, pycnidia and stromata. Commonwealth Mycological Institute, Kew (UK)

38. Sutton BC, Dyko BJ (1989) Revision of Hendersonula. Mycol Res 93:466-488

\section{Figures}



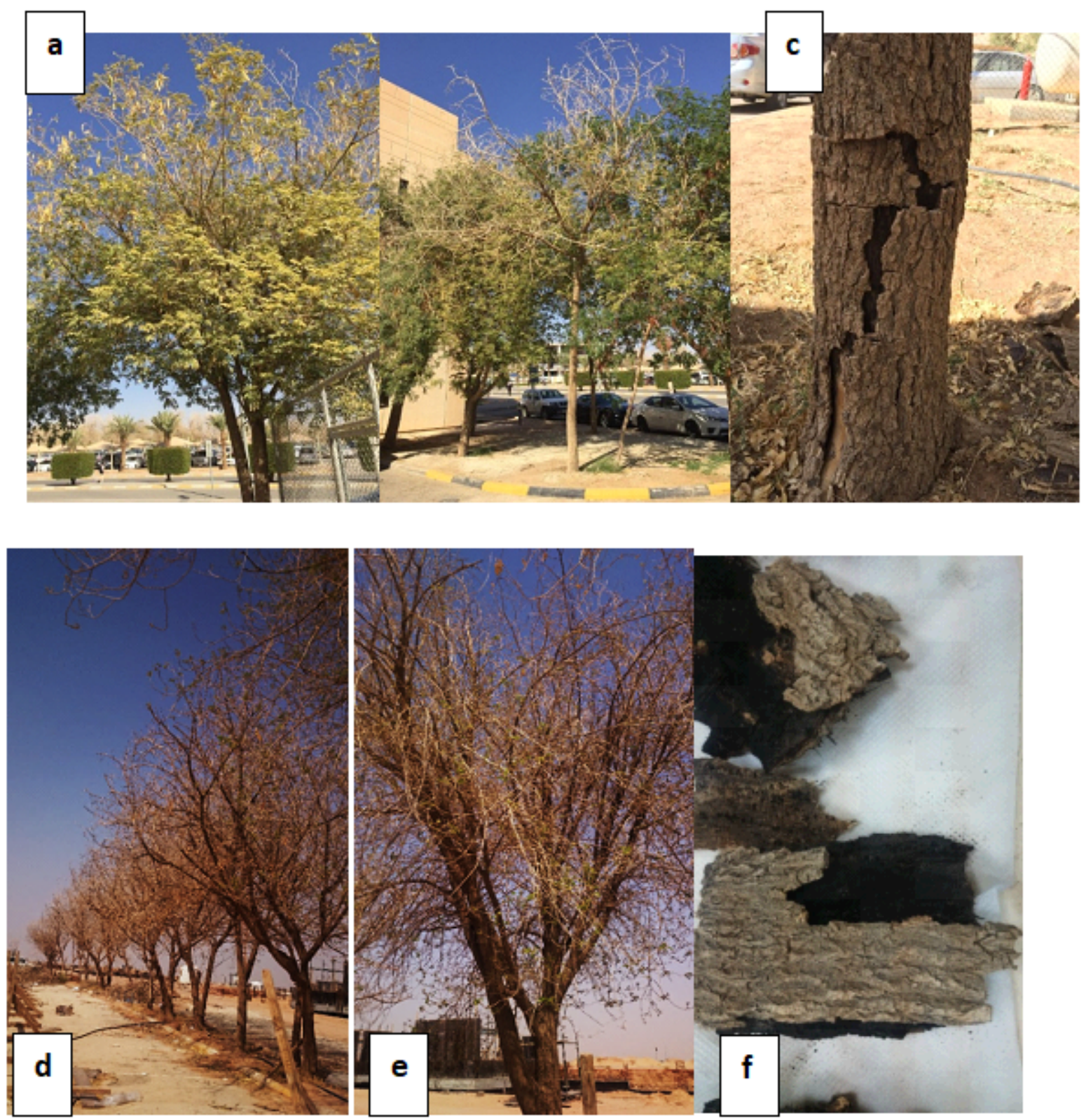

\section{Figure 1}

aBranches of A. lebbeckinfectedwith N.dimidiatumKSA.bMain stem infectionof A. lebbeck by N.dimidiatumKSA.cCracking of the trunk;d - e f Black fungalstructures with a black mass ofsporeserupting from the bark of the tree. 




a

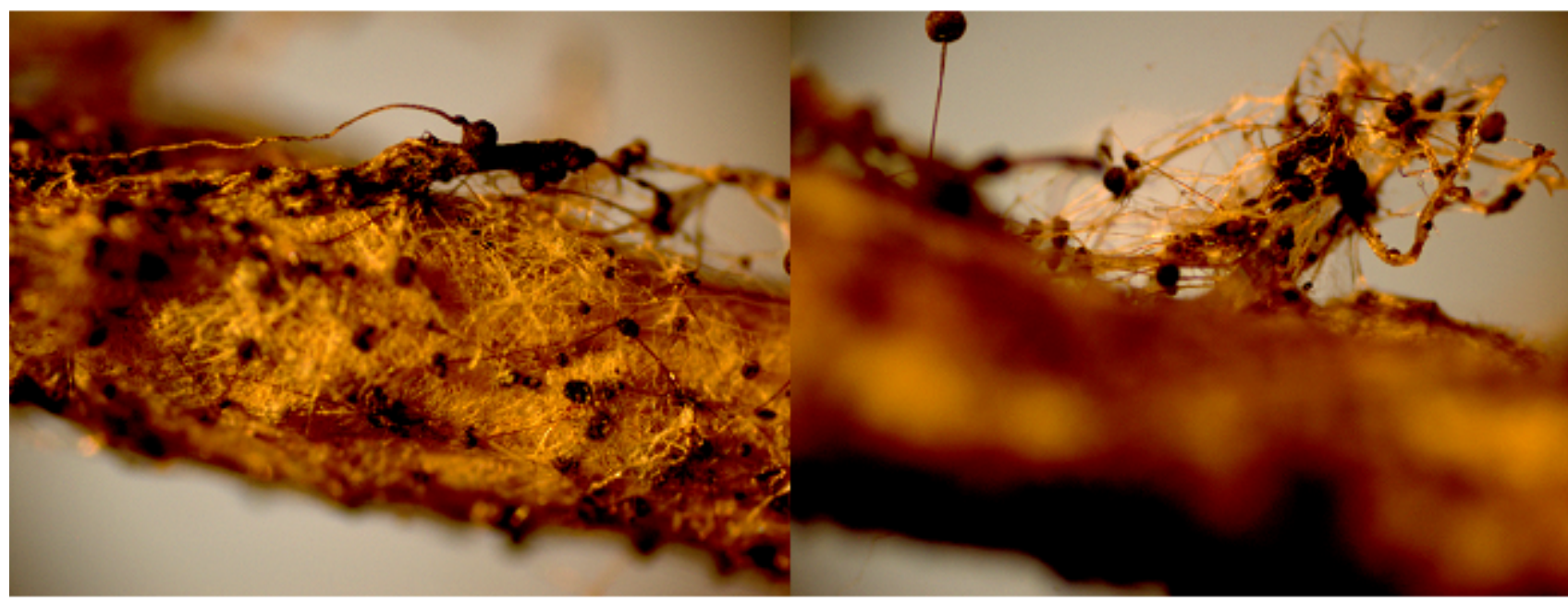

C

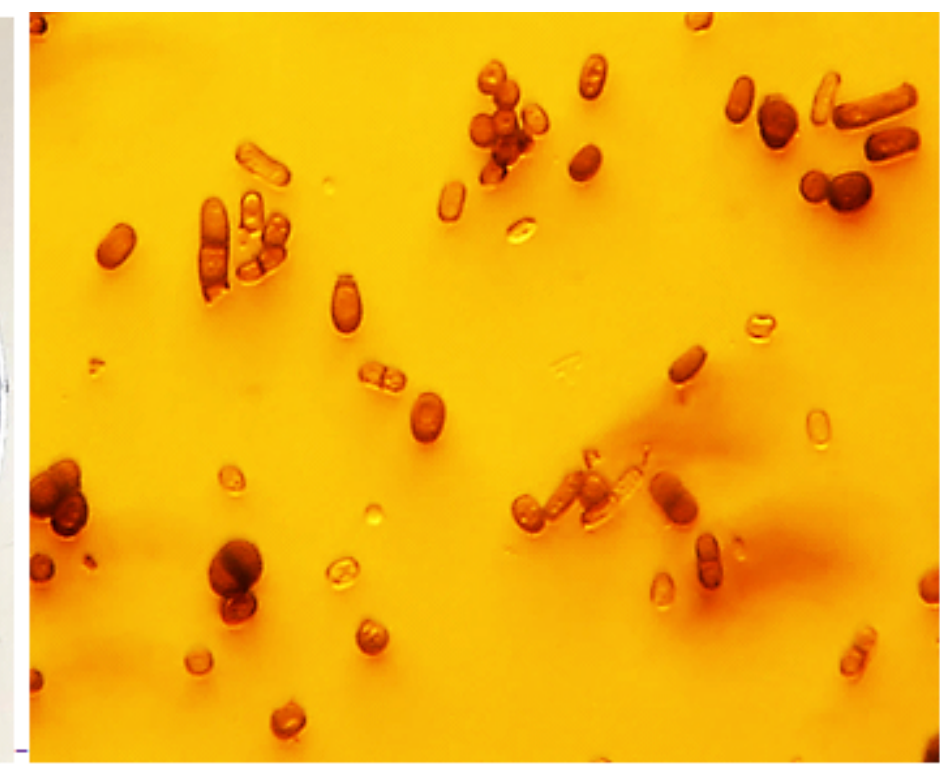

b

\section{Figure 2}

NeoscytalidiumdimidiatumKSA(a)Culture of $\mathrm{N}$. hyalinumon PDA after three daysincubation at $25^{\circ} \mathrm{C}$. (b)Immature hyaline pycnidial conidia, fragmented and with central band.(c)Conidiomata formed on casuarina needle in culture.(d)Arthricchains of coelomycetousconidia. remained free of any symptoms. 

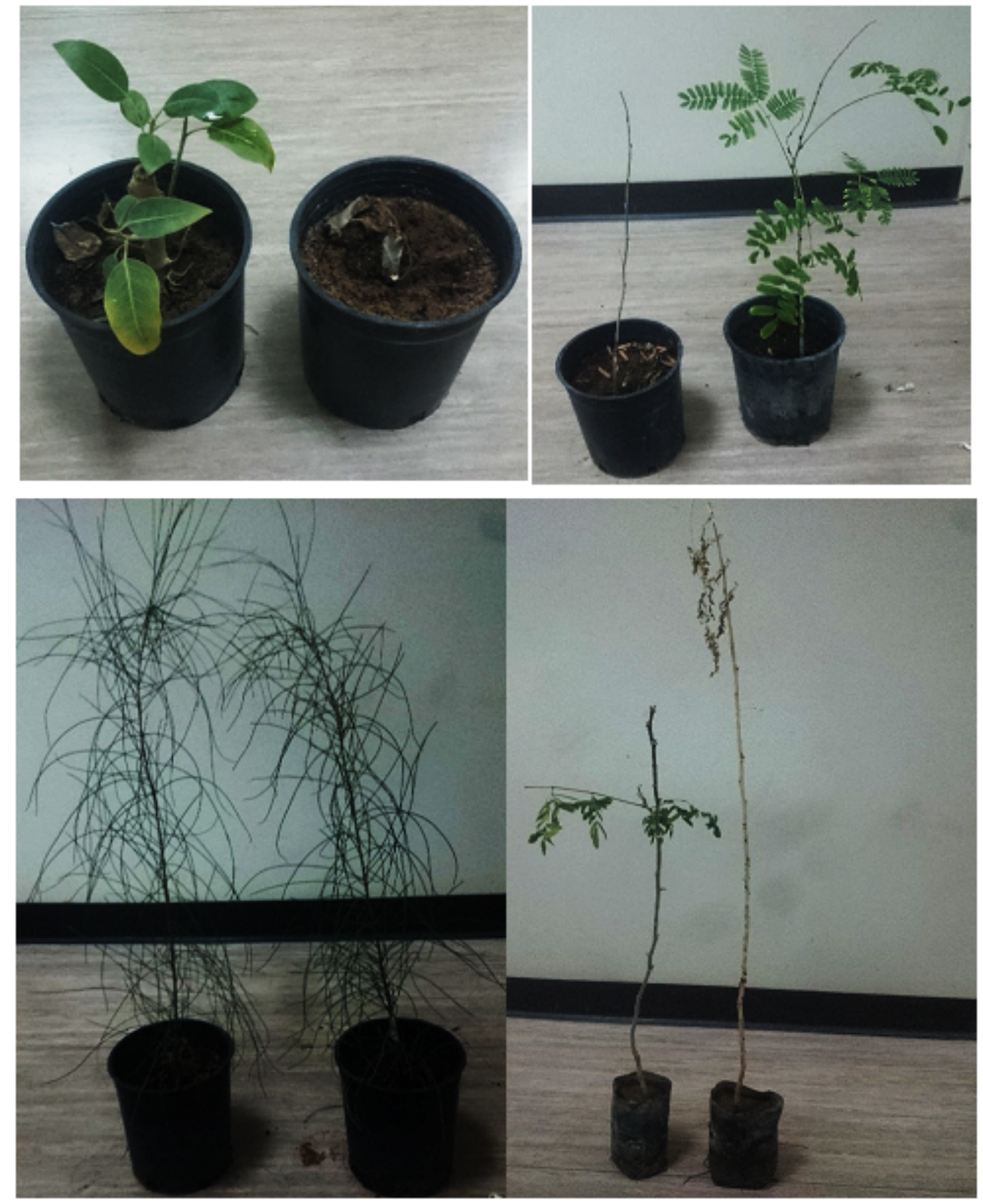

\section{Figure 3}

aHost rangesymptoms of wilting in Ficus infectoria.bDiseased plants in the field; c - d Plants wilting.e fDead plants. $g$-kNecrotic symptoms on the vascular system. 
97 Lasiodiplodia jatrophicola, CBS 176.26, KX464629

Lasiodiplodia jatrophicola, CBS 111.13, KX464628 Lasiodiplodia parva, CBS 495.78, KX464632

$100-$ Lasiodiplodia egyptiacae, BOT10, JN814424

- Lasiodiplodia margaritacea, CBS122519, EU144065

Lasiodiplodia mahajangana, CPC 4421, KX464630

Lasiodiplodia theobromae, CBS 131.33, KX464635

Lasiodiplodia mahajangana, MUCL 16086, KX464631

Lasiodiplodia theobromae, CBS 142.52, KX464637

Lasiodiplodia theobromae, CBS 287.47, KX464639

10 - Lasiodiplodia theobromae, CBS 289.56, KX464640

Lasiodiplodia hormozganensis, CBS177.89, KX464627

Lasiodiplodia vitis, PvPa, KX464642

Lasiodiplodia sterculiae, CBS 342.78 , KX464634

Lasiodiplodia pseudotheobromae, CBS374.54, KX464633

Lasiodiplodia theobromae, CBS 141.49, KX464636

Lasiodiplodia theobromae, DSM 3288, KX464638

96 Lasiodiplodia theobromae, UAMH 6554, KX464641

90 Diplodia mutila, UCROK732, JQ517317

90 Diplodia mutila, UCROK1429, JQ512121

- Diplodia bulgarica, CBS 124135, GQ923820

100 Diplodia allocellula, CMW36478, JQ239384

100 Diplodia alatafructa, CMW22627 FJ888444

89 L Diplodia alatafructa, CMW22721, FJ888446

100 Diplodia quercivora, BL8, JX894229

3 Diplodia quercivora, BL9, JX894230

Diplodia corticola, CBS 112547, DQ458872

901 Tiarosporella urbis-rosarum, CMW36477, JQ239394

100 Tiarosporella urbis-rosarum, CMW36478, JQ239395

Tiarosporella tritici, CBS $118719, \mathrm{KF} 531809$
Tiarosporella graminis, CBS $118718, \mathrm{KF} 531807$

0. Botryobambusa fusicoccum, MFLUCC 11-0143, JX646857

Botryobambusa fusicoccum, MFLUCC 11-0657, JX646858

Pseudofusicoccum olivaceum, CMW20881, FJ888437

100 Pseudofusicoccum olivaceum, CMW22637, FJ888438

Pseudofusicoccum violaceum, CMW20436, FJ888440

Pseudofusicoccum violaceum, CMW22679, FJ888442

99- Dothiorella dulcispinae, CMW36461, JQ239388

Dothiorella dulcispinae, CMW36462, JQ239389

97 - Dothiorella dulcispinae, CMW36460, JQ239387

- Dothiorella thailandica, MFLUCC 11-0438, JX646861

100 Dothiorella brevicollis, CMW36463, JQ239390

Dothiorella brevicollis, CMW36464, JQ239391

Dothiorella pretoriensis. CMW36481, JQ239393

100 Neofusicoccum arbuti, CBS 116131, KF531792

Neofusicoccum arbuti, CBS 117090, KF531791

100. Macrophomina phaseolina, CBS 227.33, KF531804

Macrophomina phaseolina, CBS 162.25, KF531803

100 r Botryosphaeria agaves, MFLUCC 10-0051, JX646855

Botryosphaeria agaves, MFLUCC 11-0125, JX646856

100 Botryosphaeria scharifii, IRAN1543C, JQ772056

Botryosphaeria scharifii, IRAN1529C, JQ772057

90 - Botryosphaeria dothidea, PD 97/14304, KX464555

90 Botryosphaeria fusispora, MFLUCC 11-0507, JX646853

Botryosphaeria fusispora, MFLUCC 10-0098, JX646854

Neoscytalidium dimidiatum, CBS 251.49, KF531797

Neoscytalidium dimidiatum, CBS 145.78, KF531795

Neoscytalidium dimidiatum, UAMH 6802, KX464765

Neoscytalidium dimidiatum, CBS125616, KX464763

- Neoscytalidium dimidiatum, CBS 499.66, KF531798

Neoscytalidium hyalinum (?), CMM3607, KF226688

$100-$ Neoscytalidium dimidiatum, DSM104095,

Neoscytalidium novaehollandiae, CBS122071, EF585580

Neoscytalidium novaehollandiae, CBS122610, EF585578

Neoscytalidium dimidiatum (?), CBS125695, KX464764

Neoscytalidium novaehollandiae, CBS122072, EF585581

Cophinforma atrovirens, MFLUCC 11-0655, JX646866

Cophinforma atrovirens, MFLUCC 11-0425, JX646865

Cophinforma mamane, CBS 117444, KF531801

Saccharata proteae, CBS 115206, KF531789

0.10 substitutions/site

\section{Figure 4}

Maximum Likelihood phylogenetic tree calculated from the analysis of the combined elongation factor alpha 1 gene region sequence data for 71species and isolates of Botryosphaeriaceae. Bootstrap values for maximum likelihoodgreater than $80 \%$ areindicated above the nodes. IsolateDSM104095from this studyis indicated in bold. Isolates of the fungus within one clade are indicated in the box. 